\title{
RAZÃO DE PERDAS DE SOLO E FATOR C PARA AS CULTURAS DE SOJ A E TRIGO EM TRÊS SISTEMAS DE PREPARO EM UM CAMBISSOLO HÚMICO ALUMÍNICO(1)
}

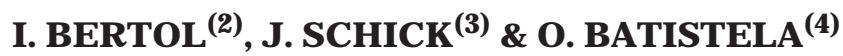

\begin{abstract}
RESUMO
Utilizando dados obti dos em experimento de perdas de solo eágua sob chuva natural em Lages (SC), de novembro de 1992 a outubro de 1998, calcularam-se a razão de perdas de solo (RPS) e o fator C da equação universal de perda de solo, para três sistemas de preparo do solo e duas culturas. Foram estudados os tratamentos aração+duas gradagens $(A+G)$, escarificaçãotgradagem $(E+G)$ e semeadura direta (SDI ), submetidos à sucessão das culturas de soja (Glycine max) e trigo (Triticum aestivum L.), comparados à aração + duas gradagens sem culturas (SSC), sobre um Cambissolo Húmico alumínico com declividade média de $0,102 \mathrm{~m} \mathrm{~m}^{-1}$. 0 ciclo de ambas as culturas foi dividido em cinco estádios, com igual intervalo de tempo entre eles. Tanto as RPS quanto os fatores C variaram amplamente entre os sistemas de preparo do solo e entre os estádios durante o ciclo das culturas, bem como entre os ciclos na mesma cultura e entre as culturas, indicando forte efeito do manejo do solo, da época do ano, da cultura e da chuva sobre essas variáveis. Os valores médios de RPS na cultura de soja foram de 0,1711, 0,1061 e 0,0477 Mg ha $\mathrm{Mg}^{-1} \mathrm{ha}^{-1}$, para a A + G, E + G e SDI, respectivamente, enquanto, para o trigo, as referidas RPS, para os respectivos sistemas de preparo do solo, foram de $0,2416,0,1874$ e 0,0883 . Os valores médios do fator $C$, para os respectivos

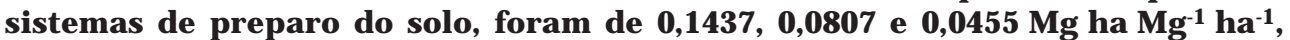

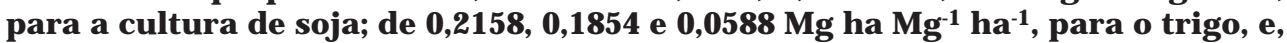

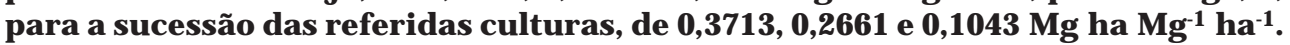

Termos de indexação: equação universal de perdas de solo, erosão hídrica, preparo conservacionista.

\footnotetext{
(1) Parte da Tese de Mestrado do segundo autor. Desenvol vido com recursos da FINEP/UDESC/CAPES. Apresentado na V RELACO, Florianópolis, outubro, 1999. Recebido para publicação em fevereiro de 2000 e aprovado em janeiro de 2001.

(2) Professor deUso eConservação doSolo do CAV, Universidade do Estado deSanta Catarina - UDESC. Avenida Luiz de Camões 2090, Caixa Postal 281, CEP 88520-000 Lages (SC). Bolsista do CNPq. E-mail: a2ib@cav.udesc.br

(3) MSc., Faculdade de Agronomia do CAV, UDESC.

(4) Aluno da Faculdade de Agronomia do CAV, UDESC. Bolsista de iniciação científica UDESC-PIBIC.
} 


\title{
SUMMARY: SOIL LOSS RATIO AND C FACTOR FOR SOYBEAN AND WHEAT CROPS UNDER TILLAGE SYSTEMS ON INCEPTISOL
}

\begin{abstract}
Soil and water loss under natural rainfall in Lages (SC - Brazil), from N ovember 1992 to October 1998, were used to cal culate soil loss ratio (SLR) and C factor for the Universal Soil Loss E quation (USLE) under threesoil tillagesystems and two crops. Treatments studied were plowing followed by two disking (P+D), chiseling plus disking (C+D) and no-tillage (NT), cultivated in succession with soybean (Glycine max) and wheat (Triticum aestivum L.), compared to a check plot: plowing followed by disking without crops (PDW), on an Inceptisol with $0.102 \mathrm{~m} \mathrm{~m}^{-1}$ slope. Five growing stages of crops were selected with equal interval time among them. The SLR and C factor varied among soil tillage systems, crop stages, same-crop and between-crop cycles, and indicating a strong effect of the soil management and rai infall over thosevariables. TheSLR values for soybean crop were 0.1711 , 0.1061 and 0.0477 for the $P+D, C+D$ and NT soil tillage systems, respectivedy while for wheat crop thereferred SLR val ues for therespectivesoil tillagesystems were 0.2416, 0.1874 and 0.0883 . For theabove mentioned soil tillagesystems, the C factors were $0.1437,0.0807$ and 0.0455 for the soybean crop, $0.2158,0.1854$ and 0.0588 for the wheat crop and, for the soybean/ wheat crop succession, $0.3713,0.2661$ and 0.1043 .
\end{abstract}

Index terms: universal soil loss equation, water erosion, conservation tillage.

\section{NTRODUÇÃO}

A predição da erosão hídrica é feita por modelos que podem ser empíricos ou matemáticos. Sua aplicação no planejamento de uso do sol o éútil, pois possibilita comparar as perdas efetivas de solo com a tolerância de perda permitida para determinado solo, tanto do ponto de vista agrícola, quanto ambiental. Para isso, é necessário quantificar os fatores componentes envol vidos no model o de erosão hídrica e, posteriormente, validar o referido modelo para cada local e condição edafoclimática.

A equação universal de perda de solo (USLE) é um model o empírico que possi bilita predizer a perda média anual de sol o por erosão hídrica, com base no conhecimento dos fatores locais que influenciam a erosão: erosividade da chuva e enxurrada a ela associada (fator R), susceptibilidade natural do solo à erosão (fator K), associação do comprimento da rampa e percentagem do ded ive (fator LS), cobertura e manejo do solo (fator $C$ ) e práticas conservacionistas de suporte (fator P) (Wischmeier $\&$ Smith, 1978).

Nos Estados Unidos, a USLE é amplamente utilizada no planejamento conservacionista em propriedades agrícolas, para prever a erosão hídrica (Murphree \& Mutchler, 1980). Sua aplicação é obrigatória pel os produtores rurais daquele país que desejarem usufruir de incentivos oferecidos pelos órgãos oficiais. No Brasil, ela nãoésistematicamente usada com esse objetivo, certamente por falta de dados suficientes para o dimensionamento de seus fatores, o que dificulta a alimentação do modelo. Em Santa Catarina, noentanto, foi publicado um manual prático com uma estimativa dos fatores da USLE (Pundek, 1994), visando ao treinamento de extensionistas rurais desse estado.

O fator $C$ para uma cultura, em determinado sistema de manejo e local específicos, representa o efeito da cobertura e manejo do solo na redução da erosão hídrica e é determinado na USLE por meio do produto da razão de perda de solo (RPS) pela fração do índice de erosividade anual ( $\left.\mathrm{FEI}_{30}\right)$ referente ao ciclo da cultura em estudo (Wischmeier \& Smith, 1978). A RPS expressa o quociente entre as perdas de solo ocorridas em determinado sistema de manejo estudado e as ocorridas num solo sem cultura e descoberto, variando, portanto, de zero a um. $\mathrm{A} \mathrm{FEI}_{30}$ é expressa em decimal e, por isso, também varia de zero a um, significando a percentagem do índice de erosividade que produziu a erosão utilizada no cálculo da respectiva RPS. Assim, o fator C da USLE varia de zero a um, aproximando-se de zero, nos sistemas de manejo conservacionistas, e de um, nos sistemas convencionais e não-conservacionistas.

O fator $\mathrm{C}$ varia amplamente de acordo com a variação da erosividade e erodibilidade, para cada cultura e tipo de manejo e cultivo do solo. Assim, há grande dificuldade na determinação desse fator em virtude das inúmeras combinações possíveis de erosividades, culturas, sistemas de cultivo etipos de preparo e manejo, para cada solo.

Trabalhando sobre um Latossolo Roxo em condições de chuva natural, em Campinas (SP), Dechen et al. (1981) constataram que, em geral, as gramíneas foram mais eficazes do que as leguminosas na diminuição das perdas de solo, em 
todos os estádios de crescimento das culturas, quando comparadas com o solo sem cultura. Para um Litólico eutrófico localizado em Caruaru (PE), Margolis et al. (1985), trabalhando sob chuva natural, obtiveram valores do fator C da USLE menores na semeadura direta do que nos demais sistemas de manejo do solo, sendo a cobertura do sol o com capim-sempre-verde o sistema mais eficaz na redução da erosão, em todos os estádios de crescimento das culturas.

Analisando um Latossolo Vermelho-Escuro em condições de chuva natural, em Planaltina (DF), Dedecek et al. (1986) concluíram que a vegetação permanente, seguida da soja em semeadura direta, foi o sistema de manejo mais eficaz na redução das perdas de solo do que os demais sistemas de manejo, traduzindo-se em menores valores de razão de perda de solo, em todos os estádios de crescimento das culturas.

Levien et al. (1990), trabalhando sob chuva simulada sobre um Podzól ico Vermel ho-Amarelo, em Guaíba (RS), concluíram que o estádio crítico da cultura do milho, em relação à erosão hídrica, é o primeiro mês após a semeadura da cultura.

Trabalhando com chuva natural sobre um Latossolo Roxo, em Dourados (MS), Hernani et al. (1997) constataram a maior eficácia da semeadura direta, em relação aos demais sistemas de manejo do solo, na redução da erosão hídrica, em todos os estádios de crescimento das culturas de trigo e soja. Também DeMaria \& Lombardi Neto (1997), trabal hando com chuva natural sobre um Latossolo Roxo em Campinas (SP), obtiveram, para a cultura de milho, valores do fator $C$ variando de 0,025 a $0,156 \mathrm{Mg}$ ha $\mathrm{Mg}^{-1} \mathrm{ha}^{-1}$, conforme as variações edafoclimáticas e de sistemas de manejo do solo, enquanto Nascimento \& Lombardi Neto (1999), trabal hando sobre os mesmos solos e local, constataram que a mucuna preta foi mais eficaz do que a crotalária e labelabe no controle da erosão hídrica, traduzindo-se em menor razão de perda de solo.

O objetivo deste trabal ho foi calcular a RPS e o fator $C$, em condições de chuva natural, para os sistemas de preparo do solo com aração + duas gradagens, escarificação + gradagem e semeadura direta, cultivados com soja e trigo em sucessão, num Cambissolo Húmico alumínico, visando à sua utilização no modelo da USLE para a predição da perda de sol o na região de Lages (SC).

\section{MATERIAL E MÉTODOS}

O experimento foi realizado entre novembro de 1992 e outubro de 1998, no Campus do Centro de Ciências Agroveterinárias de Lages (SC), situado a 27은 'de latitude sul e 5020' de longitude oeste, com 937 m de altitude média, na região do Planalto Sul Catarinense, onde o clima é do tipo $\mathrm{Cfb}$, segundo a classificação de Köeppen. O solo no local do experimento é um Cambissolo Húmico alumínico argiloso horizonte $A$ moderado, com substrato composto de siltitos + argilitos e declividade média de 0,102 $\mathrm{m} \mathrm{m}^{-1}$, descrito em Bertol (1994).

A pós a correção do sol o com cal cário para el evar opH a 6,0, as parcelas experimentais de erosão foram cultivadas com a sucessão de culturas milho/trigo/ milho de novembro de 1988 a outubro de 1992 e, a partir daí, parte da área experimental foi utilizada no presente estudo. Os tratamentos de preparo do solo foram distribuídos ao acaso e executados no sentido paralelo ao declive, conforme a filosofia de obtenção dos dados para a USLE.

Os tratamentos de preparo do sol o, sem repetição, consistiram em: uma aração + duas gradagens $(A+G)$ duas vezes ao ano, com a sucessão de culturas trigo/soja; uma escarificação + uma gradagem $(E+G)$ duas vezes aoano, com a sucessão de culturas trigo/soja; semeadura direta (SDI), com a sucessão de culturas trigo/soja, quando o solo não recebia preparo algum e o controle de plantas indesejáveis era feito manual mente ou com herbicidas específicos. Outrotratamento, com duas repetições, foi executado com uma aração+duas gradagens duas vezes ao ano, na mesma época de preparo do solo e semeadura das culturas nos demais tratamentos, mantido sem cultura e livre de vegetação e de crosta superficial (SSC) (parcela-padrão da USLE). O desencrostamento e o controle de plantas indesejáveis eram feitos com ancinho e enxada, respectivamente. Assim, foram utilizadas cinco unidades experimentais neste trabalho.

A cultura de soja foi semeada em linhas no sentido paralelo ao declive, espaçadas $0,5 \mathrm{~m}$, com semeadora manual ("saraquá"), tendo recebido, em média, 140 e $150 \mathrm{~kg} \mathrm{ha}^{-1}$ cultivo-1 $^{-1}$ de superfosfato triplo e cloreto de potássio, respectivamente. As produtividades médias foram de aproximadamente 2,4 e 3,4 Mg ha-1 de grãos e massa seca de resíduos, respectivamente. A cultura de trigo foi semeada a Ianço, com $120 \mathrm{~kg} \mathrm{ha}^{-1}$ de sementes, tendo recebido, em média, 150 e $170 \mathrm{~kg} \mathrm{ha}^{-1}$ cultivo-1 de superfosfato triplo e cloreto de potássio, respectivamente, além de $100 \mathrm{~kg} \mathrm{ha}^{-1}$ de uréia em cobertura. As produtividades médias atingi ram aproximadamente 1,8 e 6,3 $\mathrm{Mg} \mathrm{ha}^{-1}$ de grãos e massa seca de resíduos, respectivamente.

A unidade experimental constituiu-se de uma parcela com dimensões de 22,1 × 3,5 m, delimitada lateralmente e na extremidade superior por chapas galvanizadas cravadas $10 \mathrm{~cm}$ no solo e, na extremidade inferior, por um sistema coletor de enxurrada, composto de uma calha para receber o material erodido, conectada por um cano de PVC a um primeiro tanque, com capacidade de $750 \mathrm{~L}$, de sedi mentação, situado seis metros abaixo da parcela. 
Este, por sua vez, estava ligado, por meio de um divisor de enxurrada tipo "Geib" com novejanelas, a um segundo tanque, também com capacidade de $750 \mathrm{~L}$ de armazenagem.

A coleta e o processamento das amostras de enxurrada para a quantificação das perdas de solo e água foram feitos seguindo o método proposto por Cogo (1978). As perdas de sol o observadas no campo foram ajustadas para o declive de $0,09 \mathrm{~m} \mathrm{~m}^{-1}$ (parcela-padrão da USLE) pela seguinte equação, proposta por Wischmeier \& Smith (1978):

$$
\mathrm{S}=0,065+4,56 \operatorname{sen} \theta+65,41(\operatorname{sen} \theta)^{2}
$$

em que

$\mathrm{S}=$ fator grau do declive da USLE, definido pela relação de perda de solo entre uma parcela com declive qualquer e outra com declive de $0,09 \mathrm{~m} \mathrm{~m}^{-1}$ (parcela-padrão) e

$\theta=$ ângulo de declive do terreno.

Portanto, no caso em questão, a equação que proporcionou tais ajustes, sugerida por Bertol (1994), tendo como exemplo uma parcela com declive de $0,10 \mathrm{~m} \mathrm{~m}^{-1}$, foi dada por:

$$
a_{0,09 m^{-1}}=0,8342 \times a_{0,102 m^{-1}}
$$

em que

$a_{0,09 \mathrm{~mm}^{-1}}=$ perda de solo ocasionada por uma chuva qualquer, ajustada para o declive de 0,09 $\mathrm{m} \mathrm{m}^{-1}$;

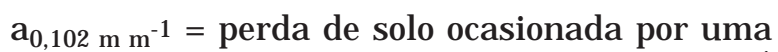
chuva qual quer, ocorrida no declive de 0,102 $\mathrm{m} \mathrm{m}^{-1}$ da parcela experimental e

0,8342 =fator de ajuste correspondente.

Para o cál culo da erosividade $\left(\mathrm{EI}_{30}\right)$, estudaramse chuvas erosivas individuais, conceituadas por Wischmeier (1959) e Wischmeier \& Smith (1978). Após terem sido cotadas as chuvas em segmentos de intensidade uniforme, calculou-se sua energia cinética por meio de programa computacional (Cataneo et al., 1982), seguindo-se o método proposto por Wischmeier \& Smith (1978). Para expressar o resultado em unidades métricas, utilizou-se a equação sugerida por F oster et al. (1981), ou seja:

$$
E=0,119+0,0873 \log _{10} I
$$

em que

$$
\begin{aligned}
& \mathrm{E}=\underset{\mathrm{Mj} m \mathrm{~mm} h \mathrm{a}^{-1} \mathrm{~h}^{-1} \mathrm{e}}{ } \\
& \mathrm{I}=\text { intensidade da chuva, } \mathrm{mm} \mathrm{h}^{-1} \text {. }
\end{aligned}
$$

Para obter o fator $C$, na definição dos estádios de crescimento durante o ciclo das culturas, deve-se considerar a percentagem de cobertura do solo (Wischmeier \& Smith, 1978). Neste experimento, no entanto, não foram feitas as determinações da cobertura pela copa das plantas, como sugere ométodo supracitado. Assim, para estabelecer os referidos estádios, adotou-se um procedimento semel hanteao de Wischmeier (1960), ou seja, o cicl o de cada cultura foi dividido em cinco estádios, com igual tempo de duração em cada um deles, para cada cultivo.

A RPS em cada estádio do ciclo das culturas foi calculada pelo quociente entre a perda de solo ocorrida no tratamento com determinada cultura e a ocorrida na parcela-padrão da USLE. A FEI 30 , em cada estádio do ciclo das culturas, foi obtida pelo quociente entre o valor da erosividade, $\mathrm{EI}_{30}$, que causou a perda de solo em cada um dos estádios no cicl o das culturas, eo valor total da erosividade, $\mathrm{EI}_{30}$, ocorrida no ciclo das referidas culturas. O fator $\mathrm{C}$, para cada estádio durante o ciclo das culturas, foi calculado pelo produto da RPS e $\mathrm{FEI}_{30}$ do referido estádio. O somatório dos valores do fator $C$ dos estádios do ciclo permitiu obter ofator $\mathrm{C}$ da referida cultura. Somando os val ores do fator $\mathrm{C}$ das culturas detrigo esoja, obteve-se ofator $C$ anual da sucessão de culturas, para cada sistema de manejo do solo.

\section{RESULTADOS E DISCUSSÃO}

Os tratamentos de preparo do solo com culturas diminuíram a erosão hídrica em $94 \%$ em relação ao SSC, na média dos sistemas de preparo e dos tipos de cultura (Quadro 1), concordando com resultados obtidos por Bertol (1994). No caso da SDI , a referida redução foi de $98 \%$, e, no da $E+G$ e A + G, de 94 e $91 \%$, respectivamente, considerando a média das culturas estudadas. I sto é explicado pelo efeito das culturas que, por meio dos resíduos vegetais da parte aérea, protegeram o sol o contra os agentes er osivos, quando mantidos na superfície e, quando incorporados, contribuíram, juntamente com as raízes, para a provável melhoria da estrutura do solo, aumentando sua resistência à erosão hídrica.

As perdas de sol o nos tratamentos com culturas foram relativamente baixas, independentemente do sistema de preparo do solo e do tipo de cultura (Quadro 1), comparadas à tolerância de perda desse solo determinada por Bertol \& Almeida (2000), concordando com Bertol (1994) eSchick et al. (2000). Tal fato pode ser atribuído às grandes quantidades de resíduos culturais, especialmente de trigo, incorporadas ao solo no tratamento $A+G$, semiincorporadas na $E+G$ e mantidas na superfície na SDI (Schick et al., 2000), o que provavel mente contribuiu para aumentar a resistência do solo à erosão nesses tratamentos. Além disso, a rugosi dade superficial ocasionada pel o preparo do sol o na A + G e na ESC foi alta (Schick et al., 2000), enquanto os valores médios anuais de erosividade e volume das chuvas foram relativamente baixos (Quadro 1), comparados aos valores obtidos por Bertol (1993) para o mesmo local. 
Quadro 1. Valores médios anuais de perda de solo ajustados para a declividade média de $0,09 \mathrm{~m} \mathrm{~m}^{-1}$, erosi vidade e volume das chuvas, em diferentes preparos sobre um Cambissolo Húmico alumínico

\begin{tabular}{lcccc}
\hline Tratamento & Soja & Trigo & El 30 & Chuva \\
& \multicolumn{2}{c}{ Mg ha-1 $^{-1}$} & Mj mm ha-1 $\mathrm{h}^{-1}$ & $\mathrm{~mm}$ \\
SSC & $66,83^{(1)}$ & & 5.425 & 1.472 \\
$\mathrm{~A}+\mathrm{G}$ & 6,52 & 5,34 & 5.425 & 1.472 \\
E +G & 4,80 & 2,82 & 5.425 & 1.472 \\
SDI & 1,82 & 1,50 & 5.425 & 1.472 \\
Média & 4,38 & 3,22 & - & - \\
C.V. (\%) & 44 & 49 & - & -
\end{tabular}

(1) Média de duas repetições. SSC: sol o sem cultura (parcela-padrão da USLE); A + G: aração + duas gradagens com a sucessão de culturas soja/trigo; $\mathrm{E}+\mathrm{G}$ : escarificação + gradagem com a sucessão de culturas soja/trigo; SDI: semeadura direta com a sucessão de culturas soja/trigo.

A cultura do trigo reduziu as perdas de solo em $26 \%$ em relação à cultura da soja, na média dos sistemas de preparo do solo, com a maior redução na $E+G(41 \%)$ (Quadro 1). I sto é explicado pelas características das culturas, maior quantidade de massa vegetal produzida pelo trigo do que pela soja (Schick et al., 2000), o que ofereceu maior proteção do sol o contra os agentes erosivos durante os ciclos dessa cultura. Além disso, a erosividade média anual das chuvas foi cerca de 49\% menor no outono-inverno (época de cultivo do trigo) do quena primavera-verão (época de cultivo da soja) (Quadro 2).
A erosividade das chuvas apresentou grande variação de distribuição entre os estádios nos diversos ciclos das duas culturas, bem como entreos diversos ciclos das duas culturas eentreas culturas (Quadros 3 e4), concordando com dados de Margol is et al. (1985), Dedecek et al. (1986), DeMaria \& Lombardi Neto (1997) e Nascimento \& Lombardi Neto (1999). Em alguns ciclos, nas duas culturas e em determinados estádios, não ocorreram chuvas erosivas e, em outros, a erosividade foi bastante el evada. Assim, a erosividade variou dezero a 78,7\% $\left(\mathrm{FEI}_{30}=\right.$ zero a 0,7870) entre estádios no ciclo da soja (Quadro 3) e de zero a 74,6\% ( $\mathrm{FEI}_{30}=$ zero a 0,7461) no detrigo (Quadro 4). Essa variação na distribuição temporal da erosividadedas chuvas é normal e decorrente da variação climática, indicando a necessidade da continuidade de pesquisas dessa natureza por longo tempo (Wischmeier \& Smith, 1978).

A distribuição dos valores de perda de solo no tratamento SSC, do mesmo modo como a da erosividade, variou entre ciclos, nas duas culturas, bem como entre estádios, nos diversos ciclos das culturas e entre culturas (Quadros 3 e 4), concordando com dados de Margolis et al. (1985), Dedecek et al. (1986), DeMaria \& Lombardi Neto (1997) e Nascimento \& Lombardi Neto (1999).

Nas duas culturas, em algumas ciclos e em determinados estádios, não ocorreram perdas de solo no SSC e, em outros, as perdas foram bastante elevadas. Assim, a perda de solo no SSC variou de zero a $57.854 \mathrm{~kg} \mathrm{ha}^{-1}$ entre estádios, na cultura de soja, e dezero a $56.067 \mathrm{~kg} \mathrm{ha}^{-1}$, na do trigo, indicando que a variação na distribuição da perda de solo, no SSC, entre estádios durante os cultivos de soja e trigo, foi maior do que a variação na distribuição da erosividadeentre os respectivos estádios, concordando com dados de Murphree \& Mutchler (1980) e DeMaria \& Lombardi Neto (1997).

Quadro 2. Valores de $\mathrm{EI}_{30}$ ocorridos durante os ciclos das culturas de soja e trigo, no período de 1993 a 1998

\begin{tabular}{|c|c|c|c|}
\hline \multicolumn{2}{|c|}{ Cultura de soja } & \multicolumn{2}{|c|}{ Cultura de trigo } \\
\hline Ciclo da cultura & $\mathrm{EI}_{30}$ & Ciclo da cultura & $\mathrm{EI}_{30}$ \\
\hline Data & Mj mm ha-1 $\mathrm{h}^{-1}$ & Data & Mj mm ha-1 $h^{-1}$ \\
\hline $\begin{array}{l}20 / 12 / 92 \text { a } 11 / 06 / 93 \\
23 / 12 / 93 \text { a } 12 / 07 / 94 \\
29 / 11 / 94 \text { a } 31 / 07 / 95 \\
01 / 12 / 95 \text { a } 30 / 04 / 96 \\
16 / 11 / 96 \text { a } 30 / 04 / 97 \\
16 / 11 / 97 \text { a } 30 / 04 / 98\end{array}$ & $\begin{array}{l}2.496 \\
4.050 \\
1.498 \\
4.700 \\
4.098 \\
4.742\end{array}$ & $\begin{array}{l}12 / 06 / 93 \text { a } 22 / 12 / 93 \\
13 / 07 / 94 \text { a } 28 / 11 / 94 \\
01 / 08 / 95 \text { a } 30 / 11 / 95 \\
01 / 05 / 96 \text { a } 15 / 11 / 96 \\
01 / 05 / 97 \text { a } 15 / 11 / 97 \\
01 / 05 / 98 \text { a } 20 / 10 / 98\end{array}$ & $\begin{array}{r}2.659 \\
1.109 \\
684 \\
1.206 \\
3.185 \\
2.120\end{array}$ \\
\hline Total & 21.584 & Total & 10.963 \\
\hline Média & 3.597 & Média & 1.827 \\
\hline C.V. (\%) & 33 & & 49 \\
\hline
\end{tabular}


Quadro 3. Valores de perda de solo no solo sem cultura (SSC) ajustados para a declividade média de $0,09 \mathrm{~m} \mathrm{~m}^{-1}$, fração do $\mathrm{EI}_{30}$, razão de perda de solo e fator $\mathrm{C}$ em diferentes estádios nos ciclos culturais da soja, em três sistemas de manejo do Cambissolo Húmico alumínico

\begin{tabular}{|c|c|c|c|c|c|c|c|c|c|}
\hline \multirow{2}{*}{$\begin{array}{l}\text { Ciclo da } \\
\text { cultura }\end{array}$} & \multirow{2}{*}{$\begin{array}{l}\text { Estádio no } \\
\text { ciclo da } \\
\text { cultura }\end{array}$} & \multirow{2}{*}{ SSC } & \multirow{2}{*}{$\mathrm{FEI}_{30}$} & \multicolumn{2}{|c|}{$\mathbf{A}+\mathbf{G}$} & \multicolumn{2}{|c|}{$\mathbf{E}+\mathbf{G}$} & \multicolumn{2}{|c|}{ SDI } \\
\hline & & & & RPS & $\mathbf{C}$ & RPS & C & RPS & C \\
\hline & & $\mathrm{kg} \mathrm{ha}^{-1}$ & \multicolumn{7}{|c|}{ Mg ha $\mathrm{Mg}^{-1} \mathrm{ha}^{-1}$} \\
\hline $\begin{array}{c}20 / 12 / 92 \\
a \\
11 / 06 / 93\end{array}$ & $\begin{array}{l}1 \\
2 \\
3 \\
4 \\
5\end{array}$ & $\begin{array}{r}25,26 \\
343,64 \\
587,70 \\
257,47 \\
2.022,09\end{array}$ & $\begin{array}{l}0,2475 \\
0,4451 \\
0,1741 \\
0,0739 \\
0,0594\end{array}$ & $\begin{array}{l}0,4375 \\
0,0117 \\
0,0033 \\
0,2173 \\
0,0338\end{array}$ & $\begin{array}{l}0,1083 \\
0,0052 \\
0,0006 \\
0,0161 \\
0,0020\end{array}$ & $\begin{array}{l}0,1722 \\
0,0176 \\
0,0213 \\
0,0649 \\
0,0082\end{array}$ & $\begin{array}{l}0,0426 \\
0,0078 \\
0,0037 \\
0,0048 \\
0,0005\end{array}$ & $\begin{array}{l}0,0788 \\
0,0024 \\
0,0007 \\
0,0033 \\
0,0099\end{array}$ & $\begin{array}{l}0,0195 \\
0,0011 \\
0,0001 \\
0,0002 \\
0,0006\end{array}$ \\
\hline & Total & $3.236,16$ & 1,0000 & $0,1407^{(1)}$ & 0,1322 & $0,0568^{(1)}$ & 0,0594 & $0,0190^{(1)}$ & 0,0215 \\
\hline $\begin{array}{c}23 / 12 / 93 \\
a \\
12 / 07 / 94\end{array}$ & $\begin{array}{l}1 \\
2 \\
3 \\
4 \\
5\end{array}$ & $\begin{array}{r}157,20 \\
2.085,21 \\
258,40 \\
11.224,87 \\
23.616,11\end{array}$ & $\begin{array}{l}0,0727 \\
0,4586 \\
0,1021 \\
0,2150 \\
0,1516\end{array}$ & $\begin{array}{l}0,1293 \\
0,2506 \\
0,1729 \\
0,1276 \\
0,0699\end{array}$ & $\begin{array}{l}0,0094 \\
0,1149 \\
0,0177 \\
0,0274 \\
0,0106\end{array}$ & $\begin{array}{l}0,1396 \\
0,1188 \\
0,0696 \\
0,0023 \\
0,0092\end{array}$ & $\begin{array}{l}0,0101 \\
0,0545 \\
0,0071 \\
0,0005 \\
0,0014\end{array}$ & $\begin{array}{l}0,0504 \\
0,0569 \\
0,0365 \\
0,0007 \\
0,0016\end{array}$ & $\begin{array}{l}0,0037 \\
0,0261 \\
0,0037 \\
0,0002 \\
0,0002\end{array}$ \\
\hline & Total & $37.341,79$ & 1,0000 & $0,1501^{(1)}$ & 0,1800 & $0,0679(1)$ & 0,0736 & $0,0292^{(1)}$ & 0,0339 \\
\hline $\begin{array}{c}29 / 11 / 94 \\
a \\
31 / 07 / 95\end{array}$ & $\begin{array}{l}1 \\
2 \\
3 \\
4 \\
5\end{array}$ & $\begin{array}{r}1.559,08 \\
1.162,21 \\
33,96 \\
60,17 \\
4,35\end{array}$ & $\begin{array}{l}0,1342 \\
0,5684 \\
0,0612 \\
0,0908 \\
0,1454\end{array}$ & $\begin{array}{l}0,1589 \\
0,2452 \\
0,4985 \\
0,4801 \\
0,1057\end{array}$ & $\begin{array}{l}0,0213 \\
0,1394 \\
0,0305 \\
0,0436 \\
0,0154\end{array}$ & $\begin{array}{l}0,4544 \\
0,1169 \\
0,1917 \\
0,1461 \\
0,1264\end{array}$ & $\begin{array}{l}0,0610 \\
0,0664 \\
0,0117 \\
0,0133 \\
0,0184\end{array}$ & $\begin{array}{l}0,0465 \\
0,1059 \\
0,1293 \\
0,1305 \\
0,0943\end{array}$ & $\begin{array}{l}0,0062 \\
0,0602 \\
0,0079 \\
0,0118 \\
0,0137\end{array}$ \\
\hline & Total & $2.819,77$ & 1,0000 & $0,2977^{(1)}$ & 0,2502 & $0,2071^{(1)}$ & 0,1708 & $0,1013^{(1)}$ & 0,0998 \\
\hline $\begin{array}{c}01 / 12 / 95 \\
a \\
30 / 04 / 96\end{array}$ & $\begin{array}{l}1 \\
2 \\
3 \\
4 \\
5\end{array}$ & $\begin{array}{r}418,22 \\
34.738,57 \\
1.815,25 \\
18.113,09 \\
12.356,99\end{array}$ & $\begin{array}{l}0,2083 \\
0,3106 \\
0,0965 \\
0,3349 \\
0,0497\end{array}$ & $\begin{array}{l}0,4597 \\
0,0347 \\
0,3412 \\
0,0080 \\
0,0196\end{array}$ & $\begin{array}{l}0,0958 \\
0,0108 \\
0,0329 \\
0,0027 \\
0,0010\end{array}$ & $\begin{array}{l}0,1468 \\
0,0372 \\
0,0728 \\
0,0025 \\
0,0000\end{array}$ & $\begin{array}{l}0,0306 \\
0,0116 \\
0,0070 \\
0,0008 \\
0,0000\end{array}$ & $\begin{array}{l}0,3002 \\
0,0069 \\
0,0458 \\
0,0027 \\
0,0000\end{array}$ & $\begin{array}{l}0,0625 \\
0,0021 \\
0,0044 \\
0,0009 \\
0,0000\end{array}$ \\
\hline & Total & $67.442,12$ & 1,0000 & $0,1726^{(1)}$ & 0,1432 & $0,0519(1)$ & 0,0500 & $0,0711^{(1)}$ & 0,0699 \\
\hline $\begin{array}{c}16 / 11 / 96 \\
a \\
30 / 04 / 97\end{array}$ & $\begin{array}{l}1 \\
2 \\
3 \\
4 \\
5\end{array}$ & $\begin{array}{r}8,94 \\
177,66 \\
57.488,75 \\
15.813,16 \\
0,00\end{array}$ & $\begin{array}{l}0,0466 \\
0,1076 \\
0,7870 \\
0,0588 \\
0,0000\end{array}$ & $\begin{array}{l}0,1700 \\
0,2259 \\
0,0140 \\
0,0055 \\
0,0000\end{array}$ & $\begin{array}{l}0,0079 \\
0,0243 \\
0,0110 \\
0,0003 \\
0,0000\end{array}$ & $\begin{array}{l}0,8400 \\
0,1623 \\
0,0107 \\
0,0037 \\
0,0000\end{array}$ & $\begin{array}{l}0,0391 \\
0,0175 \\
0,0084 \\
0,0002 \\
0,0000\end{array}$ & $\begin{array}{l}0,0503 \\
0,1540 \\
0,0037 \\
0,0004 \\
0,0000\end{array}$ & $\begin{array}{l}0,0023 \\
0,0166 \\
0,0029 \\
0,0000 \\
0,0000\end{array}$ \\
\hline & Total & $73.488,51$ & 1,0000 & $0,0831^{(1)}$ & 0,0435 & $0,2033^{(1)}$ & 0,0652 & $0,0457^{(1)}$ & 0,0218 \\
\hline $\begin{array}{c}16 / 11 / 97 \\
a \\
30 / 04 / 98\end{array}$ & $\begin{array}{l}1 \\
2 \\
3 \\
4 \\
5\end{array}$ & $\begin{array}{r}3.703,84 \\
1.008,13 \\
26.592,71 \\
22.663,63 \\
57.853,59\end{array}$ & $\begin{array}{l}0,0782 \\
0,0688 \\
0,2799 \\
0,2451 \\
0,3280\end{array}$ & $\begin{array}{l}0,7092 \\
0,0260 \\
0,0168 \\
0,0124 \\
0,1469\end{array}$ & $\begin{array}{l}0,0555 \\
0,0018 \\
0,0047 \\
0,0030 \\
0,0482\end{array}$ & $\begin{array}{l}0,0380 \\
0,0219 \\
0,0031 \\
0,0053 \\
0,1787\end{array}$ & $\begin{array}{l}0,0030 \\
0,0015 \\
0,0009 \\
0,0013 \\
0,0586\end{array}$ & $\begin{array}{l}0,0203 \\
0,0049 \\
0,0009 \\
0,0031 \\
0,0709\end{array}$ & $\begin{array}{l}0,0016 \\
0,0003 \\
0,0003 \\
0,0008 \\
0,0233\end{array}$ \\
\hline & Total & $111.821,9$ & 1,0000 & $0,1823^{(1)}$ & 0,1132 & $0,0494^{(1)}$ & 0,0653 & $0,0200^{(1)}$ & 0,0263 \\
\hline Média(1) & & $49.358,38$ & 1,0000 & 0,1711 & 0,1437 & 0,1061 & 0,0807 & 0,0477 & 0,0455 \\
\hline C.V. (\%) & & 80 & 0 & 38 & 44 & 66 & 51 & 63 & 65 \\
\hline
\end{tabular}

$\mathrm{FEI}_{30}$ : fração do índice de erosividade, $\mathrm{EI}_{30}$, no estádio da cultura; A + G: aração + duas gradagens; E + G: escarificação + gradagem; SDI : semeadura direta; RPS: razão de perda de solo entre um tratamento qualquer e o sol o sem cultura; C: fator C = produto da RPS pela $\mathrm{FEI}_{30}$.

(1) Média dos valores dos estádios durante o ciclo da cultura.

Essa maior variação nas perdas de solo no tratamento SSC do que nas erosividades das chuvas deve-se provavelmente à variabilidade da umidade antecedentedosolonomomentodeocorrência daschuvas.
Durante o ciclo da soja (Quadro 3), não houve, em geral, correspondência entre erosividades e perdas de sol o no SSC, na maioria dos estádios durante os ciclos da cultura, ou seja, em poucas ocasiões 
Quadro 4. Valores de perda de solo no solo sem cultura (SSC) ajustados para a declividade média de $0,09 \mathrm{~m} \mathrm{~m}^{-1}$, fração do $\mathrm{EI}_{30}$, razão de perda de solo e fator $\mathrm{C}$ em diferentes estádios nos ciclos culturais do trigo, em três sistemas de manejo do Cambissolo Húmico alumínico

\begin{tabular}{|c|c|c|c|c|c|c|c|c|c|}
\hline \multirow{2}{*}{$\begin{array}{l}\text { Ciclo da } \\
\text { cultura }\end{array}$} & \multirow{2}{*}{$\begin{array}{l}\text { Estádio no } \\
\text { ciclo da } \\
\text { cultura }\end{array}$} & \multirow{2}{*}{ SSC } & \multirow{2}{*}{$\mathrm{FEI}_{30}$} & \multicolumn{2}{|c|}{$\mathbf{A}+\mathbf{G}$} & \multicolumn{2}{|c|}{$\mathbf{E}+\mathbf{G}$} & \multicolumn{2}{|c|}{ SDI } \\
\hline & & & & RPS & C & RPS & C & RPS & C \\
\hline & & $\mathrm{kg} \mathrm{ha}^{-1}$ & \multicolumn{7}{|c|}{ Mgha Mg-1 ha-1 } \\
\hline $\begin{array}{c}12 / 06 / 93 \\
a \\
22 / 12 / 93\end{array}$ & $\begin{array}{l}1 \\
2 \\
3 \\
4 \\
5\end{array}$ & $\begin{array}{r}56.067,24 \\
19,66 \\
70,69 \\
180,45 \\
249,35\end{array}$ & $\begin{array}{l}0,5163 \\
0,0180 \\
0,0840 \\
0,1170 \\
0,2647\end{array}$ & $\begin{array}{l}0,0732 \\
0,1083 \\
0,1415 \\
0,2592 \\
0,0339\end{array}$ & $\begin{array}{l}0,0378 \\
0,0019 \\
0,0119 \\
0,0303 \\
0,0090\end{array}$ & $\begin{array}{l}0,0350 \\
0,2808 \\
0,2659 \\
0,2607 \\
0,2238\end{array}$ & $\begin{array}{l}0,0181 \\
0,0051 \\
0,0223 \\
0,0305 \\
0,0592\end{array}$ & $\begin{array}{l}0,0084 \\
0,0732 \\
0,0521 \\
0,0403 \\
0,0118\end{array}$ & $\begin{array}{l}0,0043 \\
0,0013 \\
0,0044 \\
0,0047 \\
0,0031\end{array}$ \\
\hline & Total & $56.587,39$ & 1,0000 & $0,1232^{(1)}$ & 0,0909 & $0,2132^{(1)}$ & 0,1352 & $0,0372^{(1)}$ & 0,0178 \\
\hline $\begin{array}{c}13 / 07 / 94 \\
a \\
28 / 11 / 94\end{array}$ & $\begin{array}{l}1 \\
2 \\
3 \\
4 \\
5\end{array}$ & $\begin{array}{r}229,08 \\
11,25 \\
75,94 \\
2.330,23 \\
427,50\end{array}$ & $\begin{array}{l}0,1041 \\
0,0124 \\
0,0370 \\
0,5961 \\
0,2504\end{array}$ & $\begin{array}{l}0,0568 \\
0,6650 \\
0,2432 \\
0,0447 \\
0,1574\end{array}$ & $\begin{array}{l}0,0059 \\
0,0082 \\
0,0090 \\
0,0266 \\
0,0394\end{array}$ & $\begin{array}{l}0,0303 \\
0,5289 \\
0,1796 \\
0,0532 \\
0,1287\end{array}$ & $\begin{array}{l}0,0032 \\
0,0066 \\
0,0066 \\
0,0317 \\
0,0322\end{array}$ & $\begin{array}{l}0,0287 \\
0,2942 \\
0,0579 \\
0,0118 \\
0,0925\end{array}$ & $\begin{array}{l}0,0030 \\
0,0036 \\
0,0021 \\
0,0070 \\
0,0232\end{array}$ \\
\hline & Total & $3.074,00$ & 1,0000 & $0,2334^{(1)}$ & 0,0891 & $0,1841^{(1)}$ & 0,0803 & $0,0970^{(1)}$ & 0,0389 \\
\hline $\begin{array}{c}01 / 08 / 95 \\
a \\
30 / 11 / 95\end{array}$ & $\begin{array}{l}1 \\
2 \\
3 \\
4 \\
5\end{array}$ & $\begin{array}{r}37,87 \\
0,00 \\
1.591,40 \\
443,45 \\
0,00\end{array}$ & $\begin{array}{l}0,0531 \\
0,0000 \\
0,7461 \\
0,1564 \\
0,0444\end{array}$ & $\begin{array}{l}0,0533 \\
0,0000 \\
0,1170 \\
0,0431 \\
0,0000\end{array}$ & $\begin{array}{l}0,0028 \\
0,0000 \\
0,0873 \\
0,0067 \\
0,0000\end{array}$ & $\begin{array}{l}0,0586 \\
0,0000 \\
0,1789 \\
0,1459 \\
0,0000\end{array}$ & $\begin{array}{l}0,0031 \\
0,0000 \\
0,1334 \\
0,0228 \\
0,0000\end{array}$ & $\begin{array}{l}0,1064 \\
0,0000 \\
0,0446 \\
0,0241 \\
0,0000\end{array}$ & $\begin{array}{l}0,0056 \\
0,0000 \\
0,0333 \\
0,0038 \\
0,0000\end{array}$ \\
\hline & Total & $2.072,72$ & 1,0000 & $0,0427^{(1)}$ & 0,0968 & $0,0767^{(1)}$ & 0,1593 & $0,0350^{(1)}$ & 0,0427 \\
\hline $\begin{array}{c}01 / 05 / 96 \\
a \\
15 / 11 / 96\end{array}$ & $\begin{array}{l}1 \\
2 \\
3 \\
4 \\
5\end{array}$ & $\begin{array}{r}0,00 \\
1.225,29 \\
1.554,03 \\
2.409,37 \\
197,89\end{array}$ & $\begin{array}{l}0,0000 \\
0,2885 \\
0,4060 \\
0,2026 \\
0,1029\end{array}$ & $\begin{array}{l}0,0000 \\
0,2748 \\
0,6178 \\
0,3985 \\
0,4092\end{array}$ & $\begin{array}{l}0,0000 \\
0,0793 \\
0,2508 \\
0,0807 \\
0,0421\end{array}$ & $\begin{array}{l}0,0000 \\
0,2507 \\
0,8207 \\
0,1878 \\
0,2359\end{array}$ & $\begin{array}{l}0,0000 \\
0,0723 \\
0,3332 \\
0,0380 \\
0,0243\end{array}$ & $\begin{array}{l}0,0000 \\
0,1196 \\
0,0229 \\
0,0661 \\
0,3566\end{array}$ & $\begin{array}{l}0,0000 \\
0,0345 \\
0,0093 \\
0,0134 \\
0,0367\end{array}$ \\
\hline & Total & $5.386,58$ & 1,0000 & $0,3401^{(1)}$ & 0,4529 & $0,2990^{(1)}$ & 0,4678 & $0,1130^{(1)}$ & 0,0939 \\
\hline $\begin{array}{c}01 / 05 / 97 \\
a \\
15 / 11 / 97\end{array}$ & $\begin{array}{l}1 \\
2 \\
3 \\
4 \\
5\end{array}$ & $\begin{array}{r}43,70 \\
253,21 \\
574,66 \\
311,64 \\
10.106,00\end{array}$ & $\begin{array}{l}0,0254 \\
0,1636 \\
0,1144 \\
0,2209 \\
0,4757\end{array}$ & $\begin{array}{l}0,6288 \\
0,3691 \\
0,9087 \\
0,4887 \\
0,1333\end{array}$ & $\begin{array}{l}0,0160 \\
0,0604 \\
0,1040 \\
0,1080 \\
0,0634\end{array}$ & $\begin{array}{l}0,3514 \\
0,3400 \\
0,4218 \\
0,1628 \\
0,0357\end{array}$ & $\begin{array}{l}0,0089 \\
0,0556 \\
0,0483 \\
0,0360 \\
0,0170\end{array}$ & $\begin{array}{l}0,5529 \\
0,0552 \\
0,0695 \\
0,0091 \\
0,0497\end{array}$ & $\begin{array}{l}0,0140 \\
0,0090 \\
0,0080 \\
0,0020 \\
0,0236\end{array}$ \\
\hline & Total & $11.289,21$ & 1,0000 & $0,5057^{(1)}$ & 0,3518 & $0,2623^{(1)}$ & 0,1658 & $0,1473^{(1)}$ & 0,0566 \\
\hline $\begin{array}{c}01 / 05 / 98 \\
a \\
20 / 10 / 98\end{array}$ & $\begin{array}{l}1 \\
2 \\
3 \\
4 \\
5\end{array}$ & $\begin{array}{r}3.929,00 \\
4.140,89 \\
3.838,62 \\
11.671,78 \\
2.853,37\end{array}$ & $\begin{array}{l}0,1093 \\
0,0801 \\
0,1488 \\
0,4170 \\
0,2448\end{array}$ & $\begin{array}{l}0,1649 \\
0,2640 \\
0,1268 \\
0,2363 \\
0,2315\end{array}$ & $\begin{array}{l}0,0180 \\
0,0211 \\
0,0189 \\
0,0985 \\
0,0567\end{array}$ & $\begin{array}{l}0,0532 \\
0,1114 \\
0,0763 \\
0,1605 \\
0,0452\end{array}$ & $\begin{array}{l}0,0058 \\
0,0089 \\
0,0114 \\
0,0669 \\
0,0111\end{array}$ & $\begin{array}{l}0,0234 \\
0,1592 \\
0,1139 \\
0,1212 \\
0,0829\end{array}$ & $\begin{array}{l}0,0026 \\
0,0128 \\
0,0169 \\
0,0505 \\
0,0203\end{array}$ \\
\hline & Total & $26.433,66$ & 1,0000 & $0,2047^{(1)}$ & 0,2132 & $0,0893^{(1)}$ & 0,1041 & $0,1001^{(1)}$ & 0,1031 \\
\hline Média(1) & & $17.473,93$ & 1,0000 & 0,2416 & 0,2158 & 0,1874 & 0,1854 & 0,0883 & 0,0588 \\
\hline C.V. (\%) & & 111 & 0 & 62 & 66 & 44 & 70 & 46 & 52 \\
\hline
\end{tabular}

$\mathrm{FEI}_{30}$ : fração do índice de erosividade, $\mathrm{EI}_{30}$, no estádio da cultura; A + G: aração + duas gradagens; $\mathrm{E}$ + G: escarificação + gradagem; SDI : semeadura direta; RPS: razão de perda de solo entre um tratamento qual quer e o sol o sem cultura; C: fator C = produto da RPS pela $\mathrm{FEI}_{30}$.

(1) Média dos valores dos estádios durante o ciclo da cultura.

alta erosividade proporcionou alta perda de solo e baixa erosividade proporcionou baixa perda desolo. Isto é explicado pela provável variabilidade na umidade antecedente do solo durante os ciclos dessa cultura (primavera-verão), em cujas estações a referida umidade apresenta maior variação temporal do que no outono-inverno, no sul do Brasil. 
Durante o ciclo do trigo (Quadro 4), no entanto, houve mel hor correspondência entre erosividades e perdas de solo no SSC, na maioria dos estádios durante os ciclos da cultura, explicado da mesma forma como no caso da soja, ou seja, a umidade do solo foi provavelmente maior e menos variável no outono-inverno. Assim, durante o cultivo de trigo, em geral, alta erosividade proporcionou alta perda de sol o e baixa erosividade proporcionou baixa perda de solo no SSC. Os valores de perda de solo no SSC durante o ciclo da soja (Quadro 3) foram cerca de 2,8 vezes superi ores aos do cicl o do trigo (Quadro 4), na média dos ciclos das respectivas culturas. I sto é explicado principalmente pela erosividade, a qual foi, em média, cerca de duas vezes maior na soja do que no trigo (Quadro 2).

Os valores de RPS foram muito diferentes entre estádios, nos diversos ciclos das culturas de soja e trigo, bem como entre os ciclos das culturas e entre culturas (Quadros 3 e4), embora a erosividadetenha sido semelhante em várias dessas situações (Quadro 2), concordando com dados obtidos por DeMaria \& Lombardi Neto (1997).

Exemplificando: no estádio 1 da cultura de soja, no ciclo de 20/12/92 a 11/06/93 (Quadro 3), a erosividadeno estádio foi de $24,7 \%$ em relação à total do ciclo ( $\left.\mathrm{FEI}_{30}=0,2475\right)$, e a RPS no tratamento $\mathrm{A}+\mathrm{G}$, nesse estádio, foi de 0,4375 $\mathrm{Mg}$ ha $\mathrm{Mg}^{-1} \mathrm{ha}^{-1}$, ou seja, a perda de solo na parcela cultivada com soja, nesse estádio e tratamento, foi equivalente a $43,7 \%$ daquela ocorrida no SSC. No estádio 4 desse tratamento e cultura, no ciclo de 16/11/97 a 30/04/ 98 , no entanto, a erosividade no estádi o foi de $24,5 \%$ da total do ciclo $\left(\mathrm{FEI}_{30}=0,2451\right)$, ea RPS, no referido estádio etratamento, de 0,0124 $\mathrm{Mg}$ ha $\mathrm{Mg}^{-1} \mathrm{ha}^{-1}$, ou seja, a perda de solo na parcela cultivada com essa cultura foi equivalente a 1,2\% daquela ocorrida no SSC.

Comportamentos semel hantes foram observados na cultura do trigo (Quadro 4), cujos dados concordam com os obtidos por Dedecek et al. (1986) eDeMaria \& Lombardi Neto (1997). I sto éexplicado pelo fato de serem as perdas de solo fortemente influenciadas não só pela cobertura do solo ocasionada pela copa das plantas, mas também pelo efeito positivo das raízes na agregação do sol o e na resistência à erosão hídrica.

Além disso, tanto nos tratamentos com culturas (SDI , E + G e A + G) quanto naquele sem cultura (SSC), a erosão depende muito da umidade antecedente do solo, bem como das condições da superfície do solo (cobertura com invasoras e resíduos culturais e rugosidade superficial ocasionada por capinas mecânicas) no momento de ocorrência das chuvas.

Assim, é possível que uma precipitação em determinado estádio, imediatamente após a realização de uma capina mecânica no tratamento SSC, por exemplo, provoque nele uma perda de solo maior do que se poderia esperar se não tivesse sido recentemente capinado e, conseqüentemente, uma redução na RPS no referido estádio.

As RPS variaram com o sistema de preparo do solo, tanto para a soja (Quadro 3) quanto para o trigo (Quadro 4), concordando com Dedecek et al. (1986) e DeMaria \& Lombardi Neto (1997). Para a soja, os valores médios de RPS dos seis ciclos da cultura

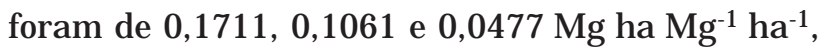
para a $A+G, E+G$ e SDI, respectivamente, enquanto, para o trigo, os referidos val ores foram de 0,2416, 0,1874 e 0,0883 $\mathrm{Mg}$ ha $\mathrm{Mg}^{-1} \mathrm{ha}^{-1}$.

Assim, na média dos seis ciclos culturais estudados, a SDI reduziu as RPS em 72 e $55 \%$ em relaçãoà $A+G$ eE $+G$, respectivamente, na cultura de soja (Quadro 3), e em 63 e $53 \%$ na de trigo (Quadro 4). I sto significa que, em relação ao SSC, a SDI perdeu uma quantidade de solo equivalente a 72 e $63 \%$ daquela perdida na $A+G$, nas culturas de soja e trigo, respectivamente, enquanto as respectivas perdas, equivalentes à $E+G$, foram de 55 e $53 \%$, oque, mais uma vez, ressalta a importância da SDI no controle das perdas de solo.

É esperado que tanto os valores de RPS quanto os de fator $\mathrm{C}$ diminuam com o desenvolvimento da cultura e proteção do sol o por meio dos aumentos da cobertura da superfície e da resistência do solo à erosão. Os dados de RPS e fator $\mathrm{C}$ constantes nos quadros 3, 4 e 5 não mostram tendência clara quanto a esse aspecto, discordando de outros trabalhos (Wischmeier \& Smith, 1978; McGregor \& Mutchler, 1983; Levien et al., 1990; DeMaria \& Lombardi Neto, 1997), nos quais se constatou que o estádio crítico de perda de solo em geral foi aquele que sucedeu à semeadura.

Segundo os resultados deste trabal ho, os estádios dos cicl os das culturas foram definidos, dividindo-se os ciclos em cinco estádios com igual duração de tempo entre eles. Portanto, não foram levados em conta os intervalos de tempo entre o preparo primário e secundário do solo, tampouco os intervalos necessários para que as culturas atingissem determinado estádio de crescimento e de proteção do sol o e os interval os após as col heitas, como fizeram os autores referidos anteriormente.

Os valores de fator $C$ para a cultura de soja (Quadros 3 e 6) foram de 0,1437, 0,0807 e 0,0455 $\mathrm{Mg}$ ha $\mathrm{Mg}^{-1}$ ha-1, para a A + G, E + G e SDI, respectivamente, enquanto, para a cultura de trigo (Quadros 4 e 6), os referidos valores para os respectivos sistemas de preparo do solo foram de $0,2158,0,1854$ e de $0,0588 \mathrm{Mg}$ ha $\mathrm{Mg}^{-1}$ ha-1 e, para a sucessão de culturas soja/trigo, foram de 0,3595,

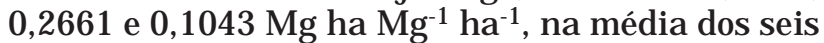
anos de cultivo, com uma ampla variação de val ores entre os anos e entre as culturas, já discutidos anteriormente. 
Quadro 5. Valores médios de perda de solo no solo sem cultura (SSC) ajustados para a declividade média de $0,09 \mathrm{~m} \mathrm{~m}^{-1}$, fração do $\mathrm{EI}_{30}$, razão de perda de solo e fator $\mathrm{C}$ para as culturas de soja e trigo, em três sistemas de manejo do Cambissolo Húmico alumínico

\begin{tabular}{|c|c|c|c|c|c|c|c|c|c|}
\hline \multirow{2}{*}{$\begin{array}{l}\text { Época } \\
\text { de cultivo }\end{array}$} & \multirow{2}{*}{$\begin{array}{l}\text { Estádio no } \\
\text { ciclo da } \\
\text { cultura }\end{array}$} & \multirow{2}{*}{ SSC } & \multirow{2}{*}{$\mathrm{FEI}_{30}$} & \multicolumn{2}{|c|}{$\mathbf{A}+\mathbf{G}$} & \multicolumn{2}{|c|}{$\mathbf{E}+\mathbf{G}$} & \multicolumn{2}{|c|}{ SDI } \\
\hline & & & & RPS & C & RPS & C & RPS & C \\
\hline & & $\mathrm{kg} \mathrm{ha}^{-1}$ & \multicolumn{7}{|c|}{ Mgha Mg-1 ha-1 } \\
\hline \multicolumn{10}{|c|}{ Cultura de soja } \\
\hline \multirow{8}{*}{$\begin{array}{l}\text { Primavera } \\
\text { Verão }\end{array}$} & 1 & 978,76 & 0,1313 & 0,3441 & 0,0497 & 0,2985 & 0,0310 & 0,0911 & 0,0160 \\
\hline & 2 & $6.585,90$ & 0,3265 & 0,1324 & 0,0494 & 0,0791 & 0,0265 & 0,0552 & 0,0177 \\
\hline & 3 & $14.462,80$ & 0,2501 & 0,1745 & 0,0162 & 0,0615 & 0,0065 & 0,0362 & 0,0032 \\
\hline & 4 & $11.355,40$ & 0,1698 & 0,1418 & 0,0155 & 0,0375 & 0,0035 & 0,0235 & 0,0023 \\
\hline & 5 & $15.975,52$ & 0,1224 & 0,0627 & 0,0129 & 0,0538 & 0,0132 & 0,0295 & 0,0063 \\
\hline & Média(1) & $9.871,68$ & 0,2000 & 0,1711 & 0,0288 & 0,1061 & 0,0161 & 0,0477 & 0,0094 \\
\hline & C.V. (\%) & 56 & 39 & 55 & 59 & 92 & 68 & 51 & 69 \\
\hline & Total & $49.358,38$ & 1,0000 & $0,1711^{(1)}$ & 0,1437 & $0,1061^{(1)}$ & 0,0807 & $0,0477^{(1)}$ & 0,0455 \\
\hline \multicolumn{10}{|c|}{ Cultura de trigo } \\
\hline \multirow{8}{*}{$\begin{array}{l}\text { Outono } \\
\text { Inverno }\end{array}$} & 1 & $10.051,15$ & 0,1347 & 0,1628 & 0,0134 & 0,0881 & 0,0065 & 0,1199 & 0,0049 \\
\hline & 2 & 941,72 & 0,0938 & 0,2802 & 0,0285 & 0,2520 & 0,0248 & 0,1169 & 0,0102 \\
\hline & 3 & $1.284,22$ & 0,2561 & 0,3592 & 0,0803 & 0,3239 & 0,0924 & 0,0602 & 0,0123 \\
\hline & 4 & $2.891,15$ & 0,2850 & 0,2451 & 0,0585 & 0,1618 & 0,0377 & 0,0454 & 0,0136 \\
\hline & 5 & $2.305,69$ & 0,2305 & 0,1609 & 0,0351 & 0,1116 & 0,0240 & 0,0989 & 0,0178 \\
\hline & Média(1) & $3.494,78$ & 0,2000 & 0,2416 & 0,0431 & 0,1874 & 0,0371 & 0,0883 & 0,0118 \\
\hline & C.V. (\%) & 96 & 37 & 31 & 55 & 47 & 79 & 34 & 36 \\
\hline & Total & $17.473,93$ & 1,0000 & $0,2416^{(1)}$ & 0,2158 & $0,1874^{(1)}$ & 0,1854 & $0,0883^{(1)}$ & 0,0588 \\
\hline
\end{tabular}

$\mathrm{FEI}_{30}$ : fração do índice de erosividade, $\mathrm{EI}_{30}$, no estádio da cultura; A + G: aração + duas gradagens; $\mathrm{E}+\mathrm{G}$ : escarificação + gradagem; SDI: semeadura direta; RPS: razão de perda de sol o entre um tratamento qual quer e o sol o sem cultura; $\mathrm{C}$ : fator $\mathrm{C}$ = produto da RPS pela $\mathrm{FEI}_{30}$.

(1) Média dos valores dos estádios durante o ciclo da cultura.

Quadro 6. Valores do fator C para cada ciclo das culturas de soja e trigo e anual para a sucessão soja/ trigo, obtidos pelo produto da razão de perda de solo e fração do $\mathrm{EI}_{30}$, em três sistemas de manejo do Cambissolo Húmico alumínico

\begin{tabular}{|c|c|c|c|c|c|c|c|c|c|}
\hline \multirow[b]{2}{*}{ Ano } & \multicolumn{3}{|c|}{ Soja } & \multicolumn{3}{|c|}{ Trigo } & \multicolumn{3}{|c|}{ Sucessão soja/trigo } \\
\hline & $\mathbf{A}+\mathbf{G}$ & $\mathbf{E}+\mathbf{G}$ & SDI & $\mathbf{A}+\mathbf{G}$ & $\mathbf{E}+\mathbf{G}$ & SDI & $\mathbf{A}+\mathbf{G}$ & $\mathbf{E}+\mathbf{G}$ & SDI \\
\hline & \multicolumn{9}{|c|}{$-\mathrm{Mg}$ ha $\mathrm{Mg}^{-1}$ ha-1 } \\
\hline 1993 & 0,1322 & 0,0594 & 0,0215 & 0,0909 & 0,1352 & 0,0178 & 0,2231 & 0,1946 & 0,0393 \\
\hline 1994 & 0,1800 & 0,0736 & 0,0339 & 0,0891 & 0,0803 & 0,0389 & 0,2691 & 0,1539 & 0,0728 \\
\hline 1995 & 0,2502 & 0,1708 & 0,0998 & 0,0968 & 0,1593 & 0,0427 & 0,3470 & 0,3301 & 0,1425 \\
\hline 1996 & 0,1432 & 0,0500 & 0,0699 & 0,4529 & 0,4678 & 0,0939 & 0,5961 & 0,5178 & 0,1638 \\
\hline 1997 & 0,0435 & 0,0652 & 0,0218 & 0,3518 & 0,1658 & 0,0566 & 0,3953 & 0,2310 & 0,0784 \\
\hline 1998 & 0,1132 & 0,0653 & 0,0263 & 0,2132 & 0,1041 & 0,1031 & 0,3264 & 0,1694 & 0,1294 \\
\hline Média & 0,1437 & 0,0807 & 0,0455 & 0,2158 & 0,1854 & 0,0588 & 0,3595 & 0,2661 & 0,1043 \\
\hline C.V. (\%) & 44 & 51 & 65 & 66 & 70 & 52 & 29 & 47 & 42 \\
\hline
\end{tabular}

A + G: aração + duas gradagens; E + G: escarificação + gradagem; SDI : semeadura direta. 
Na cultura de soja, a eficácia relativa da SDI na redução da erosão hídrica, avaliada com base no fator $C$, foi de $68 \%$, em relação à A + G, e de $44 \%$, em relaçãoà $E+G$, na média dos seis cultivos, enquanto, na cultura de trigo, a referida eficácia foi de 73 e $68 \%$, concordando com dados de Margol is et al . (1985) e DeMaria \& Lombardi Neto (1997). I sto pode ser atribuído à presença dos resíduos vegetais na superfície do sol o na SDI , os quais protegeram o solo contra os agentes erosivos, especial mente o impacto das gotas de chuva e, ainda, ao decréscimo de desagregação da superfície do solo decorrente da ausência de preparo nesse tratamento, em relação aos demais. Para a sucessão de culturas soja/trigo, a eficácia relativa da SDI supra-referida foi de $71 \%$ em relação à $A+G$ e de $61 \%$ em relação à $E+G$, explicada do mesmo modo como para as culturas de soja e trigo.

Os valores médios do fator $C$ foram maiores na cultura de trigo do que de soja, em todos os sistemas de preparo do solo (Quadro 6). A maior variação entre culturas ocorreu na $E+G$ (2,3 vezes), e a menor, na SDI (1,29 vez). Tal comportamento é explicado pela erosividade das chuvas que, em média, foi duas vezes maior no cultivo da soja do que no trigo (Quadro 2), o que ocasionou maiores perdas de solo no SSC durante os ciclos da soja (Quadro 3) do que do trigo (Quadro 4) e, conseqüentemente, menores valores de RPS na soja do que no trigo (Quadros 3, 4 e 5).

\section{CONCLUSÕES}

1. Os valores médios de RPS para a cultura de soja, considerando os sistemas de preparo do solo aração + duas gradagens, escarificação + gradagem e semeadura direta, foram, respectivamente, de 0,1711, 0,1061 e 0,0477 $\mathrm{Mg}$ ha $\mathrm{Mg}^{-1}$ ha-1 $^{-1}$, enquanto, para o trigo, os referidos valores foram de 0,2416 , 0,1874 e $0,0883 \mathrm{Mg}$ ha $\mathrm{Mg}^{-1} \mathrm{ha}^{-1}$.

2. Os valores médios de fator $C$ para a cultura de soja, considerando os sistemas de preparo do solo aração + duas gradagens, escarificação + gradagem e semeadura direta, foram, respectivamente, de 0,1437, 0,0807 e 0,0455 $\mathrm{Mg}$ ha $\mathrm{Mg}^{-1}$ ha-1 $^{-1}$, enquanto, para o trigo, os referidos valores foram de 0,2158, 0,1854 e 0,0588 Mg ha $\mathrm{Mg}^{-1}$ ha-1 $^{-1}$ e, para a sucessão de culturas soja/trigo, foram de 0,3595, 0,2661 e $0,1043 \mathrm{Mg}$ ha $\mathrm{Mg}^{-1} \mathrm{ha}^{-1}$.

\section{LITERATURA CITADA}

BERTOL, I. Índice de erosividade $\left(\mathrm{EI}_{30}\right)$ para Lages $(\mathrm{SC})-1^{\mathrm{a}}$ aproximação. Pesq. Agropec. Bras., 28:515-521, 1993.

BERTOL, I. Erosão hídrica em Cambissolo Húmico distrófico sob diferentes preparos do solo e rotação de culturas. R. Bras. Ci. Solo, 18:267-271, 1994.
BERTOL, I. \& ALMEIDA, J.A. Tolerância de perda do solo por erosão para os principais solos do estado de Santa Catarina. R. Bras. Ci. Solo, 24:657-668, 2000.

CATANEO, A.; CASTRO FILHO, C. \& ACQUAROLE, R.M. Programa para cálculo de índices de erosividade de chuvas. R. Bras. Ci. Solo, 6:236-239, 1982.

COGO, N.P. U ma contribuiçãoà metodol ogia deestudo das perdas de erosão em condições de chuva natural. I. Sugestões gerais, medição dos volumes, amostragem e quantificação de solo e água da enxurrada (1 ${ }^{a}$ aproximação). In: ENCONTRO NACIONAL DE PESQUISA SOBRE CONSERVAÇÃO DO SOLO, 2., Passo Fundo, 1978. Anais. Passo Fundo, Empresa Brasileira dePesquisa Agropecuária, 1978. p.75-98.

DEDECEK, R.A.; RESK, D.V.S. \& FREITAS J r., E. Perdas de solo, água e nutrientes por erosão em Latossolo Vermel hoEscuro dos cerrados em diferentes cultivos sob chuva natural. R. Bras. Ci. Solo, 10:265-272, 1986.

DECHEN, S.C.F.; LOMBARDI NETO, F. \& CASTRO, O.M. Gramíneas eleguminosas eseus restos culturais no controle da erosão em Latossolo Roxo. R. Bras. Ci. Solo, 5:133-137, 1981.

DeMARIA, I.C. \& LOMBARDI NETO, F. Razão de perdas de solo e fator $C$ para sistemas de manejo da cultura do milho. R. Bras. Ci. Solo, 21:263-270, 1997.

FOSTER, G.R.; MCCOOL, D.K.; RENARD, K.G. \& MOLDENHAUER, W.C. Conversion of the universal soil Ioss equation to SI metric units. J. Soil Water Conserv., 36:355-359, 1981.

HERNAI, L.C.; SALTON, J .C.; FABRÍCIO, A.C.; DEDECEK, R. $\&$ ALVES J r., M. Perdas por erosão erendimentos de soja e de trigo em diferentes sistemas de preparo de um $L$ atossolo Roxo de Dourados (MS). R. Bras. Ci. Solo, 21:667-676, 1997.

LEVIEN, R.; COGO, N.P. \& ROCKENBACH, C.A. Erosão na cultura do milho em diferentes sistemas de cultivo anterior e métodos de preparo do solo. R. Bras. Ci. Solo, 14:73-80, 1990.

MARGOLIS, E.; SILVA, A.B. \& J ACQUES, F.O. Determinação dos fatores da Equação Universal de Perdas de Solo para as condições de Caruaru (PE). R. Bras. Ci. Solo, 9:165-169, 1985.

McGREGOR, K.C. \& MUTCHLER, C.K. C factors for no-till and reduced-till corn. Trans. Am. Soc. Agric. Eng., 26:785-794, 1983.

MURPHREE, C.E. \& MUTCHLER, C.K. Cover and management factors for cotton. Trans. Am. Soc. Agric. Eng., 23:585-595, 1980.

NASCIMENTO, P.C. \& LOMBARDI NETO, F. Razão de perdas de solo sob cultivo de três leguminosas. R. Bras. Ci. Solo, 23:121-125, 1999.

PUNDEK, M. Utilização prática da equação universal de perdas de solo para as condições de Santa Catarina. In: SANTA CATARINA. Secretaria de Estado da Agricultura e Abastecimento. Manual de uso, manejo e conservação do solo e da água: projeto de recuperação, conservação e manejo dos recursos naturais em microbacias hidrográficas. 2.ed. Florianópolis, EPAGRI-Empresa dePesquisa Agropecuária e Difusão de Tecnol ogia de Santa Catarina, 1994. p.99-129. 
SCHICK, J .; BERTOL, I.; BATISTELA, O. \& BALBINOT J r., A.A. Erosão hídrica em Cambissol o Húmico alumínico submetido a diferentes sistemas de preparo e cultivo do solo- I : perdas de solo e água. R. Bras. Ci. Solo, 24:427-436, 2000.

WISCHMEIER, W.H. A rainfall erosion index for a universal soilIoss equation. Soil Sci. Soc. Am. Proc., 23:246-249, 1959.
WISCHMEIER, W.H. Cropping-management factor for a universal soil-loss equation. Soil Sci. Soc. Am. Proc., 24:322326, 1960.

WISCHMEIER, W.H. \& SMITH, D.D. Predicting rainfall erosion losses - a guide to conservation planning. Washington, USDA, 1978. 58p. (Agricultural Handbook, 537) 
I. BERTOL et al.

R. Bras. Ci. Solo, 25:451-461, 2001 